\title{
Organochlorine Pesticides in the Atmosphere and Surface Water from the Equatorial Indian Ocean: Enantiomeric Signatures, Sources, and Fate
}

\author{
Yumei Huang, ${ }^{\dagger, \S}$ Yue $\mathrm{Xu},{ }^{*}{ }^{\dagger}$ Jun $\mathrm{Li}_{\#}^{\dagger}{ }^{\dagger}$ Weihai Xu, ${ }^{\ddagger}$ Gan Zhang, ${ }^{\dagger}$ Zhineng Cheng, ${ }^{\dagger, \S}$ Junwen Liu, ${ }^{\dagger, \S}$ \\ Yan Wang, ${ }^{\dagger}$ and Chongguo Tian ${ }^{\#}$ \\ ${ }^{\dagger}$ State Key Laboratory of Organic Geochemistry, Guangzhou Institute of Geochemistry, Chinese Academy of Sciences, \\ Guangzhou, Guangdong 510640, China \\ ${ }^{\ddagger}$ CAS Key Laboratory of Marginal Sea Geology, South China Sea Institute of Oceanology, Chinese Academy of Sciences, \\ Guangzhou 510301, China \\ ${ }^{\S}$ Graduate University of Chinese Academy of Sciences, Beijing 100049, China \\ ${ }^{\#}$ Key Laboratory of Coastal Zone Environmental Processes and Ecological Remediation and Shandong Provincial Key Laboratory of \\ Coastal Zone Environmental Processes, Yantai Institute of Coastal Zone Research, Chinese Academy of Sciences, Yantai, \\ Shandong 264003, China
}

Supporting Information

ABSTRACT: Nineteen pairs of gaseous and surface seawater samples were collected along the cruise from Malaysia to the south of Bay of Bengal passing by Sri Lanka between April 12 and May 4, 2011 on the Chinese research vessel Shiyan I to investigate the latest OCP pollution status over the equatorial Indian Ocean. Significant decrease of $\alpha-\mathrm{HCH}$ and $\gamma-\mathrm{HCH}$ was found in the air and dissolved water phase owing to global restriction for decades. Substantially high levels of $p, p^{\prime}$-DDT, $o, p^{\prime}$-DDT, trans-chlordane (TC), and cis-chlordane (CC) were observed in the water samples collected near Sri Lanka, indicating fresh continental riverine input of these compounds. Fugacity fractions suggest equilibrium of $\alpha-\mathrm{HCH}$ at most sampling sites, while net volatilization for DDT isomers, TC and CC in most cases. Enantiomer fractions (EFs) of $\alpha-\mathrm{HCH}$ and $o, p^{\prime}$-DDT in the air and water samples were determined to trace the source of these compounds in the air.

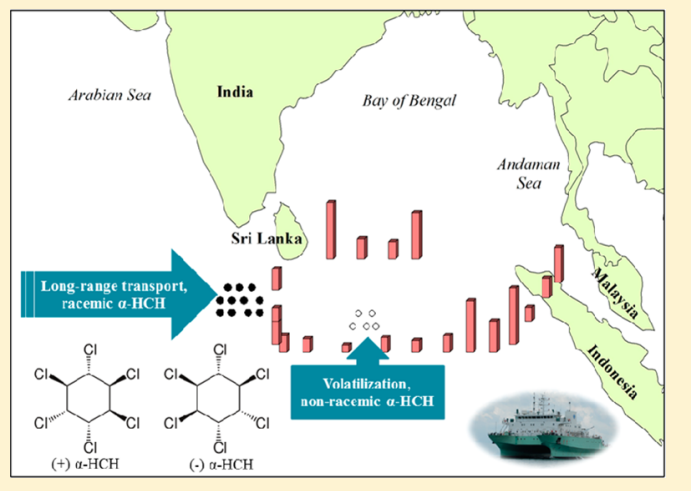
Racemic or close to racemic composition was found for atmospheric $\alpha-\mathrm{HCH}$ and $o, p^{\prime}$-DDT, while significant depletion of $(+)$ enantiomer was found in the water phase, especially for $o, p^{\prime}-\mathrm{DDT}(\mathrm{EFs}=0.310$ $\pm 0.178) .24 \%$ of $\alpha-\mathrm{HCH}$ in the lower air over the open sea of the equatorial Indian Ocean is estimated to be volatilized from local seawater, indicating that long-range transport is the main source.

\section{INTRODUCTION}

Organochlorine pesticides (OCPs) are a group of semivolatile persistent organic pollutants (POPs), which are of worldwide concern because of their persistence, bioaccumulation, and negative effects on human, animals, and plant lives. ${ }^{1}$ Due to their volatility and persistence, OCPs are subject to global distribution throughout the environment. ${ }^{2}$ The monitoring of marine POPs is of great importance. Oceans are believed to be the largest sink of POPs, ${ }^{3,4}$ which may be converted into a secondary source of particular POPs, such as dichlorodiphenyltrichloroethane $(\mathrm{DDT})^{5}$ and alpha-hexachlorocyclohexane $(\alpha-\mathrm{HCH}),{ }^{6}$ long after those compounds were banned.

Processes such as air-water exchange, atmospheric dispersion, and biogeochemical processes in seawater, play important roles in controlling the environmental fate of POPs. ${ }^{4}$ To date, many studies have been carried out on the air-water exchange and biogeochemical processes of OCPs in oceans and seas. Those studies focused on the Arctic region and subarctic area, such as the eastern Arctic Ocean, ${ }^{7,8}$ the North American Arctic Ocean, ${ }^{9,10}$ and the North Atlantic Ocean. ${ }^{8,11}$ Studies on the Chinese marginal seas have also been conducted. ${ }^{12,13}$ Although atmospheric OCPs in the equatorial Indian Ocean have also been investigated recently, ${ }^{14,15}$ study on the air-water exchange of OCPs in this area could date back to two decades ago in the Bay of Bengal and Arabian Sea conducted by Iwata et al. ${ }^{4}$ The equatorial Indian Ocean is surrounded by tropical developing countries, such as India, Sri Lanka, Malaysia, Indonesia, etc. Because a large quantity of OCPs, such as technical DDT and $\mathrm{HCH}$, was used for agricultural and

\section{Received: July 16, 2013}

Revised: October 29, 2013

Accepted: November 1, 2013

Published: November 19, 2013 


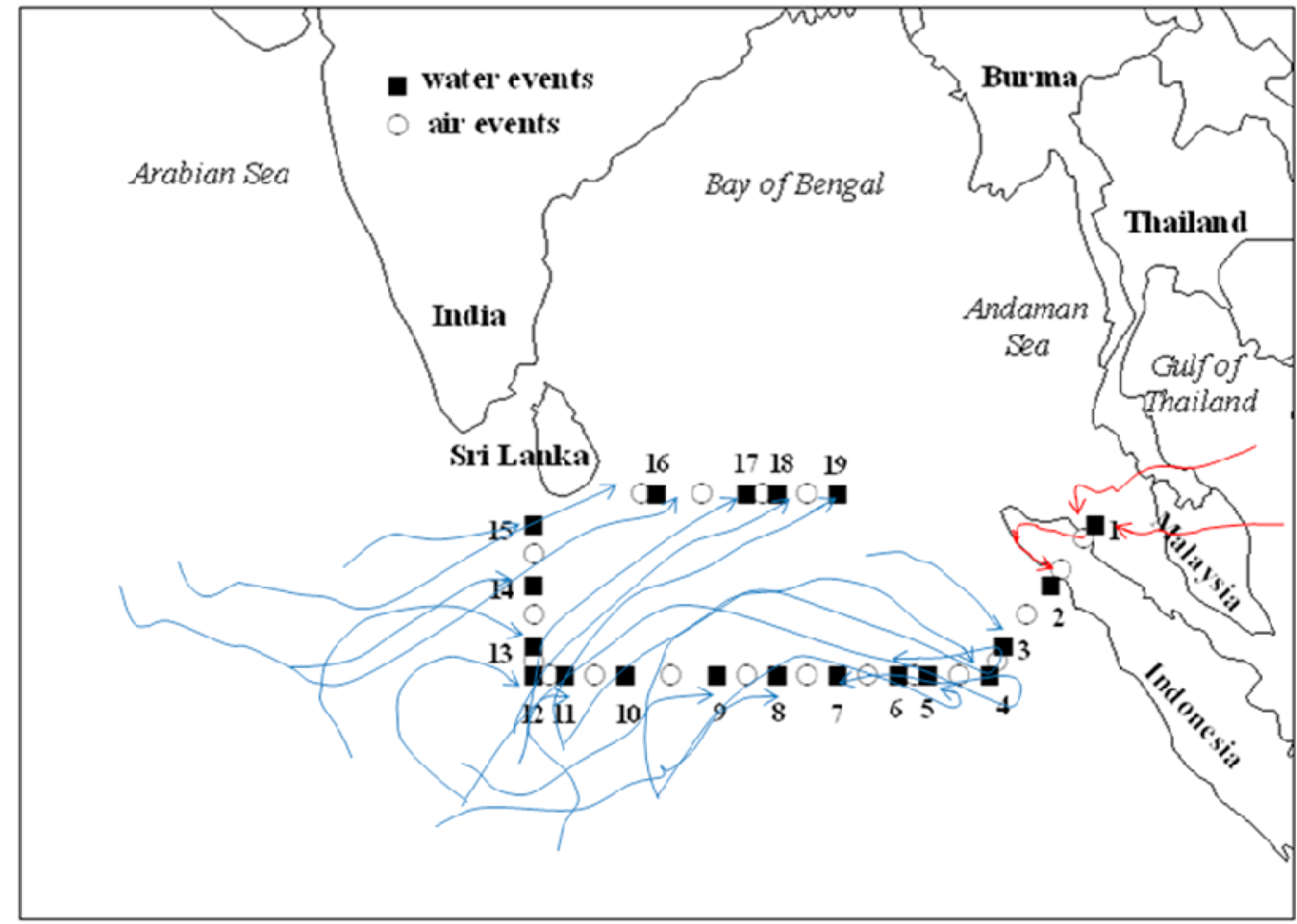

Figure 1. Sampling locations and backward trajectories (BTs) of the air masses. Three BTs were continental from Malaysia and Indonesia (red lines), and the remaining BTs were oceanic from the Indian Ocean (blue lines).

public health purpose in those countries, this area has been considered as important sources of OCPs. What is more, DDT is still allowed to be used for malaria control in India under the Stockholm Convention. ${ }^{16}$

The application of the enantiomeric compositions of some chiral pesticides has made significant progress in this field recently, in particular for $\alpha$-HCH. ${ }^{17}$ Enantiomers have identical vapor pressures, water solubility, and partition coefficients in the air, water and soil. Transport (advection, deposition, and volatilization) and abiotic reactions (photolysis, hydrolysis, $\mathrm{OH}$ radical attack) will not change enantiomer proportions, while microbial activities in the seawater would result in enantioselective degradation of chiral compounds. ${ }^{17,18}$ Therefore, chiral compounds offer special advantage for following transport and fate pathways, i.e., long-range transport vs volatilization. ${ }^{18}$

In this study, we analyzed 19 pairs of lower air and surface seawater samples collected from Malaysia to the south of Bay of Bengal passing by Sri Lanka in the equatorial Indian Ocean in 2011 on the Chinese research vessel Shiyan I to (1) obtain data of the levels of selected OCPs (HCHs, DDTs, and chlordanes) in the target area, (2) estimate the air-water exchange direction, (3) investigate the microbial degradation and hydrolysis of selected OCPs in the water phase, and (4) trace the sources of chiral $\mathrm{HCH}$ and DDT in the lower air.

\section{EXPERIMENTAL SECTION}

Sample Collection. Onboard the Chinese research vessel Shiyan I of South China Sea Institute of Oceanology, from April 12th to May 4th, 2011, 19 pairs of air and seawater samples were taken from equatorial Indian Ocean $\left(0-6^{\circ} \mathrm{E}, 80-98.5^{\circ} \mathrm{N}\right.$, Figure 1, Table S2). Air samples were taken via a high-volume air sampler placed in the windward on the foredeck of the ship. About $200-500 \mathrm{~m}^{3}$ of air was drawn through a quartz fiber filter and subsequently through a polyurethane foam (PUF) plug (i.d.: $6.5 \mathrm{~cm}$, length: $7.5 \mathrm{~cm}$, density: $0.03 \mathrm{~g} \mathrm{~m}^{-3}$ ). At each station, $70-120 \mathrm{~L}$ of surface seawater was collected in the seawater-cleaned metal bucket and filtered through a precombusted $\left(4 \mathrm{~h}\right.$ at $\left.450{ }^{\circ} \mathrm{C}\right)$ $150 \mathrm{~mm}$ diameter glass fiber filter (Gelman Type A/E, nominal pore size: $1 \mu \mathrm{m})$. Then the water sample was passed through a Teflon column (i.d.: $25 \mathrm{~mm}$, length: $20 \mathrm{~mm}$, pore size: $0.5 \mathrm{~mm}$ ) packed with about $28 \mathrm{~g}$ of pretreated resin (XAD-2 and XAD-4, $1: 1 \mathrm{v} / \mathrm{v}$ ) at the flow rate of approximate $100 \mathrm{~mL} \mathrm{~min}^{-1}$. The filters, PUFs, and XAD columns were stored at $-20{ }^{\circ} \mathrm{C}$ until analysis.

Sample Preparation and Instrumental Analysis. The PUF samples spiked with TCmX, PCB209, and ${ }^{13} \mathrm{C}-\mathrm{PCB} 141$ as recovery surrogates were Soxhlet extracted with dichloromethane (DCM) and further purified on a multilayer silica gel-alumina column. Thirty $\mathrm{mL}$ of DCM/hexane (1:1) was eluted to collected OCP fraction. The XAD resin spiked with the above surrogates was ultrasonically extracted with methanol and subsequently with DCM. The extract was then further extracted using DCM, concentrated and purified as the PUF samples. Concentrated OCP fraction was solvent exchanged to hexane, and ${ }^{13} \mathrm{C}-\mathrm{PCB} 138$ was added as an internal standard for instrumental analysis.

Achiral OCPs were measured on an Agilent 7890/7000 GC-MS/MS with a HP-5MS capillary column $(30 \mathrm{~m} \times 0.25 \mathrm{~cm} \times$ $0.25 \mathrm{~mm}$, Agilent, CA, USA). After achiral OCPs determination, the same extracts were analyzed for enantiomers of $\alpha-\mathrm{HCH}$ and $o, p^{\prime}$-DDT on the Agilent GC-MS/MS with a BGB-172 column $(15 \mathrm{~m} \times 0.25 \mathrm{~cm} \times 0.25 \mathrm{~mm}$, BGB Analytik AG, Switzerland). More information on the procedures is given in the Supporting Information (SI).

QA/QC. Three laboratory blanks, four PUF field blanks, and two XAD field blanks were analyzed. OCPs were undetectable in the laboratory blanks, and minor amounts of heptachlor, transchlordane (TC), and cis-chlordane (CC) were detected in the field blanks. For air samples, the recoveries were $97 \pm 7.2 \%, 63 \pm$ $13 \%$, and $110 \pm 11 \%$ for ${ }^{13} \mathrm{C}-\mathrm{PCB} 141, \mathrm{TCmX}$, and PCB 209, 
Table 1. Summary of Selected OCP Concentrations in the Air and Water ${ }^{a}$

\begin{tabular}{|c|c|c|c|c|c|c|}
\hline \multirow[b]{2}{*}{ compound } & \multicolumn{3}{|c|}{ gas phase $\left(\mathrm{pg} \mathrm{m}^{-3}\right)$} & \multicolumn{3}{|c|}{ water phase $\left(\mathrm{pg} \mathrm{L}^{-1}\right)$} \\
\hline & av & $\mathrm{SD}$ & range & av & SD & range \\
\hline$\alpha-\mathrm{HCH}$ & 0.77 & 0.47 & $0.21-1.7$ & 3.2 & 0.80 & $2.0-4.7$ \\
\hline$\beta$-HCH & 0.40 & 0.20 & $0.15-0.95$ & 5.4 & 2.2 & $1.6-8.9$ \\
\hline$\gamma-\mathrm{HCH}$ & 0.61 & 0.28 & $0.24-1.2$ & 2.2 & 1.3 & $0.71-6.3$ \\
\hline$\sum \mathrm{HCHs}$ & 1.78 & 0.83 & $0.76-3.4$ & 11 & 3.3 & $4.8-17$ \\
\hline heptachlor & 27 & 36 & n.d. -120 & 2.8 & 7.2 & n.d. -32 \\
\hline $\mathrm{TC}$ & 20 & 24 & $0.70-90$ & 9.4 & 26 & n.d. -120 \\
\hline $\mathrm{CC}$ & 15 & 18 & $0.88-71$ & 6.6 & 17 & n.d. -76 \\
\hline $\mathrm{TN}$ & 3.1 & 3.8 & $0.06-15$ & 2.0 & 4.6 & n.d. -21 \\
\hline $\mathrm{CN}$ & 0.48 & 0.66 & n.d. -2.8 & 0.32 & 0.48 & n.d. -2.1 \\
\hline$o, p^{\prime}-\mathrm{DDD}$ & 0.35 & 0.19 & $0.05-0.78$ & 4.1 & 10 & n.d. -44 \\
\hline$o, p^{\prime}-\mathrm{DDE}$ & 0.43 & 0.22 & $0.11-0.99$ & 48 & 120 & n.d. -510 \\
\hline$o, p^{\prime}-\mathrm{DDT}$ & 1.4 & 0.66 & $0.43-2.9$ & 330 & 840 & n.d. -3600 \\
\hline$p, p^{\prime}-\mathrm{DDD}$ & 0.72 & 0.46 & $0.15-2.2$ & 19 & 40 & $1.8-170$ \\
\hline$p, p^{\prime}-\mathrm{DDE}$ & 0.94 & 0.47 & $0.23-2.0$ & 37 & 85 & $0.30-360$ \\
\hline$p, p^{\prime}-\mathrm{DDT}$ & 4.3 & 1.8 & $1.1-8.8$ & 1600 & 4000 & $2.4-17000$ \\
\hline$\sum \mathrm{DDTs}$ & 8.1 & 3.6 & $2.2-17$ & 2000 & 5100 & $9.0-22000$ \\
\hline
\end{tabular}

respectively. For water samples, the equivalent values were $97 \pm$ $10 \%, 71 \pm 9.5 \%$, and $100 \pm 18 \%$, respectively. The reported OCP concentrations in air and seawater in this study were corrected by deducting the average values in PUF and XAD field blanks, respectively, and not recovery corrected. Instrumental and method detection limits are discussed in the Supporting Information.

For chiral analysis, racemic standards were injected repeatedly to determine the reproducibility of EF (enantiomer fraction, $\mathrm{EF}=$ peak areas of the $(+) /((+)+(-))$ enantiomers) measurements. Average EF values of the standards were $0.507 \pm 0.014$ $(n=6)$ for $\alpha-\mathrm{HCH}$ and $0.502 \pm 0.004(n=6)$ for $o, p^{\prime}$-DDT, respectively. An EF of 0.5 indicates racemic composition. If the EF for a particular sample fell outside the $95 \%$ confidence interval of the EF values for the standards (the range was $0.492-0.521$ for $\alpha$-HCH and $0.498-0.505$ for $o, p^{\prime}$-DDT), they were interpreted as not significantly different from racemic. ${ }^{19,20}$ Breakthrough of analytes from sorbent traps during air and water sampling was checked and found negligible (Supporting Information).

Air Mass Back Trajectories. NOAA's HYSPLIT model was used to assess the air mass origins along the cruise segments of the samples. ${ }^{21,22} 120 \mathrm{~h}$ back trajectories were calculated at the beginning and end of each air sample collection in coordinated universal time (UTC) at $10 \mathrm{~m}$ above sea level (Figure 1).

\section{RESULTS AND DISCUSSION}

Air Concentration and Spatial Distribution. The concentrations of selected OCPs in the air are summarized in Table 1. As shown in Figure 2, spatial distribution of $\mathrm{HCH}$ and DDT isomers was relatively uniform, with $\mathrm{H} / \mathrm{L}$ (highest/lowest) values lower than 14.5. Although continental air masses passing over Malaysia and Indonesia were observed for air samples 1 and 2, these two samples did not exhibit significantly high concentrations compared with those with open oceanic air masses (Figures 1 and 2), which may relate to the fact that technical DDT has been banned in Malaysia and Indonesia since 1990s, and $\mathrm{HCH}$ was also banned in Indonesia. ${ }^{23}$ It implies that the gaseous concentrations of $\mathrm{HCH}$ and DDTs should be measured at background levels in the equatorial Indian Ocean. The observed $\alpha-\mathrm{HCH}$ and $\gamma-\mathrm{HCH}$ values in this study were lower than those reported over the equatorial Indian Ocean in 2005, ${ }^{14}$ the Andaman Sea and Bay of Bengal in 2008, ${ }^{15}$ the Northwest
Indian Ocean in $2008,{ }^{15}$ and the East and South China Seas in $2008,{ }^{15}$ and significantly lower than those measured two decades ago over the Bay of Bengal and Arabian Sea ${ }^{4}$ (Table S3) due to phase out of technical $\mathrm{HCH} .{ }^{16}$ Compared with the reports monitored over the open seas recently, $\alpha-\mathrm{HCH}\left(0.77 \pm 0.47 \mathrm{pg} \mathrm{m}^{-3}\right)$ in this study was lower than those observed over the North Atlantic and the Arctic Ocean in $2004\left(2.7 \pm 1.4 \mathrm{pg} \mathrm{m}^{-3}\right){ }^{8}$ the North Atlantic in $2007\left(3.4 \pm 2 \mathrm{pg} \mathrm{m}^{-3}\right)^{15}$ and in $2008(4.9 \pm$ $\left.1.2 \mathrm{pg} \mathrm{m}^{-3}\right),{ }^{11}$ the South Atlantic in $2007\left(2.3 \pm 2.4 \mathrm{pg} \mathrm{m}^{-3}\right),{ }^{15}$ the North Pacific Ocean in $2008\left(26-56 \mathrm{pg} \mathrm{m}^{-3}\right),{ }^{24}$ and the Canadian Arctic Ocean during 2007 to $2008\left(7.5-48 \mathrm{pg} \mathrm{m}^{-3}\right){ }^{18}$ Like $\alpha-\mathrm{HCH}$, the concentration of $\gamma-\mathrm{HCH}$ was also lower than those observed in the open seas of the high latitude (Table S3). The concentration of $p, p^{\prime}$-DDT in this study $\left(1.1-8.8 \mathrm{pg} \mathrm{m}^{-3}\right)$ was higher than the value reported for the Northwest Indian Ocean $\left(0.1-0.85 \mathrm{pg} \mathrm{m}^{-3}\right),{ }^{15}$ similar to those for the equatorial Indian Ocean in $2005\left(4.2-12.5 \mathrm{pg} \mathrm{m}^{-3}\right)^{14}$ and the Andaman Sea and Bay of Bengal in $2008\left(0.27-6.7 \mathrm{pg} \mathrm{m}^{-3}\right){ }^{15}$ and was lower than that in the East and South China Seas $\left(0.64-80 \mathrm{pg} \mathrm{m}^{-3}\right){ }^{15}$ Significantly higher $p, p^{\prime}$-DDT concentration of $19-590 \mathrm{pg} \mathrm{m}^{-3}$ was reported over the Bay of Bengal and Arabian Sea in 1989. ${ }^{4}$ Compared to the values of the other open seas, the $p, p^{\prime}$-DDT concentration in the equatorial Indian Ocean was higher than those over the North Atlantic and Arctic Ocean in 2004 (n.d. $\left.-0.22 \mathrm{pg} \mathrm{m}^{-3}\right){ }^{8}$ North Atlantic in $2007\left(0.8 \pm 0.6 \mathrm{pg} \mathrm{m}^{-3}\right),{ }^{15}$ and South Atlantic Ocean $\left(0.4 \pm 0.4 \mathrm{pg} \mathrm{m}^{-3}\right),{ }^{15}$ which may be relative to the proximity to the surrounding area with large amounts of historical DDT application. What is more, India still holds exemptions for DDT usage in malaria control recently, indicating possible fresh sources. ${ }^{16}$ With respect to chlordane isomers, significant variation was observed $(p=0.003)$ (Figure 2$)$, with $\mathrm{H} / \mathrm{L}$ values up to 129,81 , and 250, respectively, for TC, CC, and trans-nonachlor $(\mathrm{TN})$, indicating continuing regional emissions of technical chlordane. Heptachlor ranged from n.d. to $120 \mathrm{pg} \mathrm{m}^{-3}$ and dominated (38-50\%) in the samples with high concentrations (Figure 2), suggesting that use of technical heptachlor was another source, and besides being a component of technical chlordane, ${ }^{25}$ heptachlor was also used alone as termiticide. $^{26}$ TC $(8-15 \%)$ and CC $(8-13 \%)$ were the most abundant components of technical chlordane. ${ }^{25}$ The TC/CC ratio in the air over the equatorial Indian Ocean was $1.39 \pm 0.29$, 

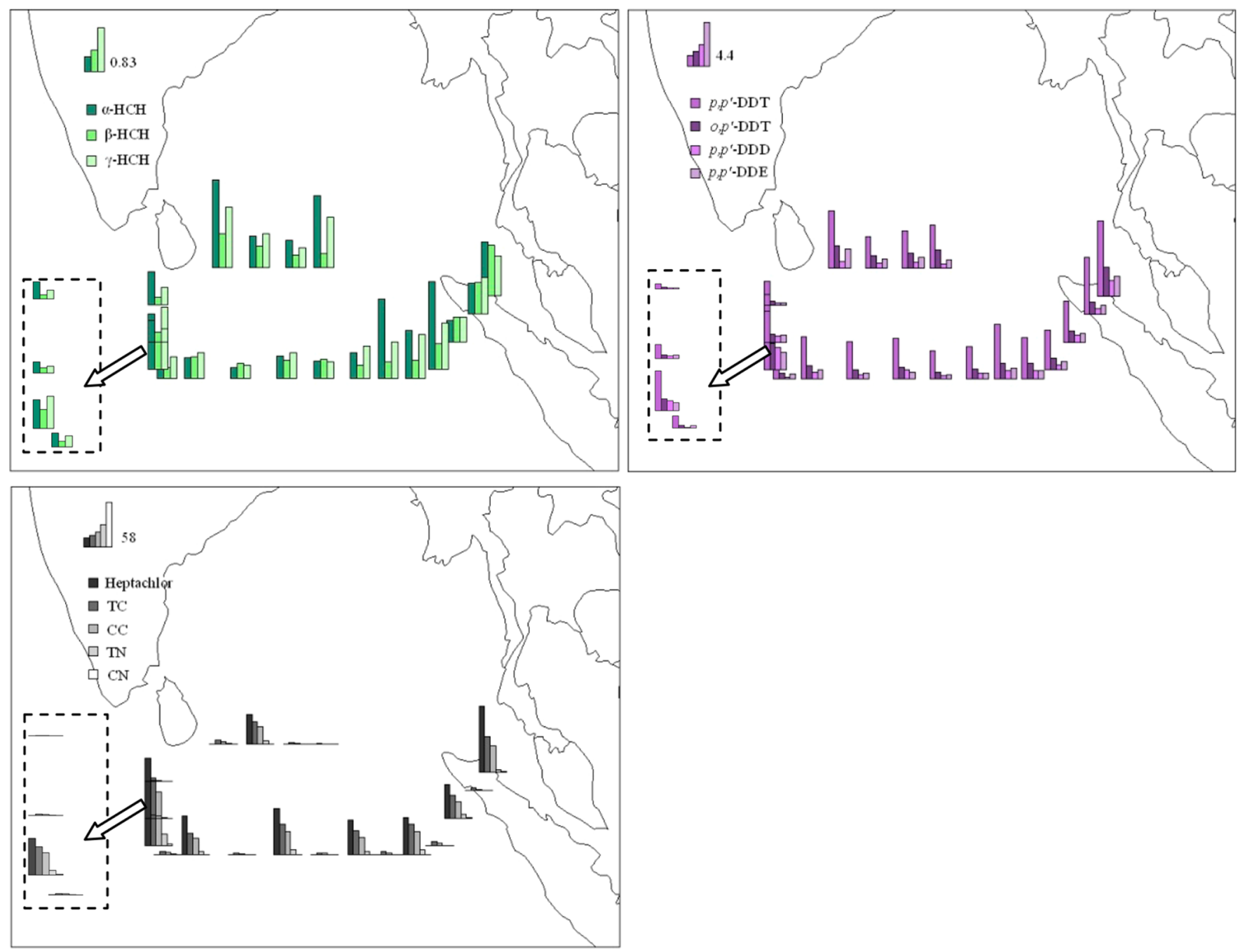

Figure 2. Spatial distribution of OCPs in low layer air samples $\left(\mathrm{pg} \mathrm{m}^{-3}\right)$.

higher than the reported values of technical chlordane made in the United States $(1.16-1.18)^{26}$ and in China $(0.76-0.87){ }^{27}$

TC and CC are the mostly measured chlordane isomers in surface ocean and lower air studies. As demonstrated in Table S3, the concentrations of TC $\left(20 \pm 24 \mathrm{pg} \mathrm{m}^{-3}\right)$ and $\mathrm{CC}(15 \pm$ $\left.18 \mathrm{pg} \mathrm{m}^{-3}\right)$ in this study were comparable to those over the Northwest Indian Ocean and the East and South China Seas in $2008^{15}$ but higher than the values reported over the Bay of Bengal and Arabian Sea in 1989, ${ }^{4}$ the Andaman Sea and Bay of Bengal in 2008, ${ }^{15}$ the North Atlantic and Arctic Ocean after 2004, ${ }^{8,11,15}$ and the South Atlantic in $2007 .{ }^{15}$ Like DDT compounds, the higher values of TC and CC in the study area than those reported in the Arctic and subarctic regions may be relative to the extensive usage of technical chlordane in the surrounding countries. ${ }^{28}$ In addition, the long-range atmospheric transport potential may be another influencing factor. Gioia et al. ${ }^{15}$ predicted shorter atmospheric residence times of $p, p^{\prime}$-DDT, TC, and $\mathrm{CC}$ than $\alpha-\mathrm{HCH}$ and $\gamma-\mathrm{HCH}$ in the Andaman Sea and Bay of Bengal.

Water Concentration and Temporal Trends. As shown in Table 1, the dissolved water phase concentrations of $\alpha-\mathrm{HCH}$, $\beta$ - $\mathrm{HCH}$, and $\gamma-\mathrm{HCH}$ were $3.2 \pm 0.8 \mathrm{pg} \mathrm{L}^{-1}, 5.4 \pm 2.2 \mathrm{pg} \mathrm{L}^{-1}$, and $2.2 \pm 1.3 \mathrm{pg} \mathrm{L}^{-1}$, respectively. Spatially, uniform distribution was found for $\mathrm{HCH}$ isomers in the water phase. The concentrations of $\alpha-\mathrm{HCH}$ and $\gamma-\mathrm{HCH}$ in the water samples were lower than those reported in the North Atlantic and Arctic Ocean $(13 \pm 16.3$ pg L ${ }^{-1}$ for $\alpha-\mathrm{HCH}$ and $4.7 \pm 5.6 \mathrm{pg} \mathrm{L}^{-1}$ for $\left.\gamma-\mathrm{HCH}\right),{ }^{8}$ the North Atlantic $\left(57.6 \pm 28.9 \mathrm{pg} \mathrm{L}^{-1}\right.$ for $\alpha-\mathrm{HCH}$ and $20.4 \pm 9.6 \mathrm{pg} \mathrm{L}^{-1}$ for $\gamma-\mathrm{HCH})^{11}$ and the Canadian Arctic Ocean (456-1013 pg L $^{-1}$ for $\alpha-\mathrm{HCH}$ and $150 \pm 254 \mathrm{pg} \mathrm{L}{ }^{-1}$ for $\left.\gamma-\mathrm{HCH}\right){ }^{18}$ The Arctic Ocean was suggested to be the last refuge for $\alpha-\mathrm{HCH}^{29}$

Substantial variations were found for DDT and chlordane compounds (Figure 3). For example, $p, p^{\prime}$-DDT concentrations ranged from 2.4 to $17000 \mathrm{pg} \mathrm{L}^{-1}$, and $o, p^{\prime}$-DDT concentrations ranged from n.d. to $3600 \mathrm{pg} \mathrm{L}{ }^{-1}$. p, $p^{\prime}$-DDT dominated in most samples, except for the four samples collected from Stations 4, 9, 10 and 11 , where its metabolite $p, p^{\prime}$-DDD was the most abundant, followed by $p, p^{\prime}$-DDT. In those four samples, $\sum$ DDT concentrations fell in the low end, ranging from $9.0 \mathrm{pg} \mathrm{L}^{-1}$ to $12 \mathrm{pg} \mathrm{L}^{-1}$. Significantly high concentrations were observed near Sri Lanka (Stations 15 and 16) (Figure 3). Riverine input from India under the role of coastal currents may be a potential source for them, because DDT has been completely banned in Sri Lanka since 1986, while India is still allowed to use DDT in public health sectors for malaria control with a maximum of $10000 \mathrm{t}$ per year under the Stockholm Convention until an economically viable alternative is available. ${ }^{16}$ For example, the national malaria program (NAMP) used $3750 \mathrm{t}$ of DDT in 2001, in rural and periurban areas for residual spraying. ${ }^{30}$ Unlike $\mathrm{HCH}$ isomers, the concentrations of $p, p^{\prime}$-DDE, TC, and CC in the North Atlantic 

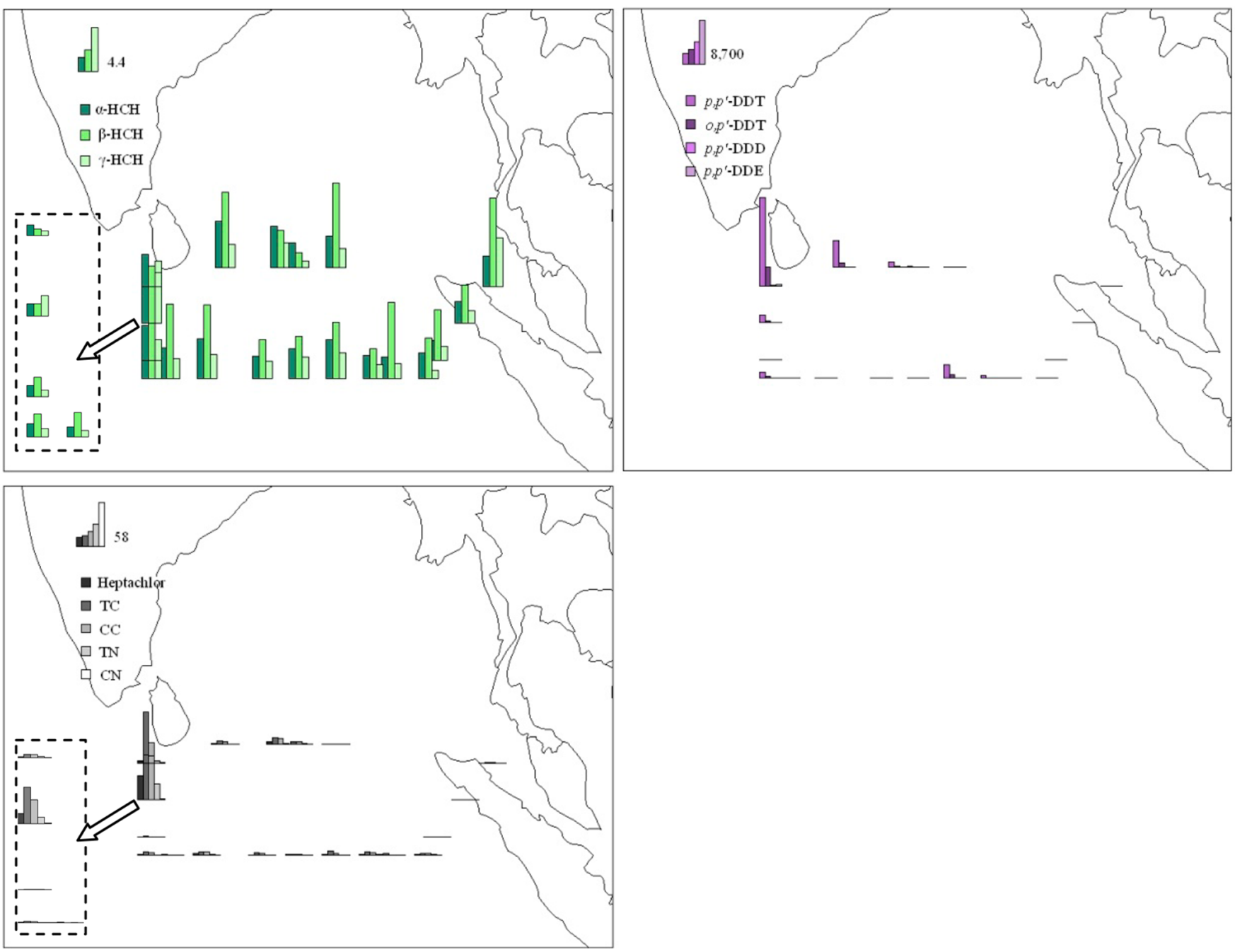

Figure 3. Spatial distribution of OCPs in surface water samples $\left(\mathrm{pg} \mathrm{L}^{-1}\right)$.

and Arctic Ocean were much lower than the values in the present study (Table S3).

There were fewer measurements of OCPs in the equatorial Indian Ocean seawater than in the air. Considering the samples with exceptional high concentrations (Stations 15 and 16 for DDTs and Station 14 for chlordanes) as outliers in this study, the average concentrations of $\alpha-\mathrm{HCH}$ and $\gamma-\mathrm{HCH}$ at other sites were substantially lower than the data reported in the Bay of Bengal and Arabian Sea in 1989, ${ }^{4}$ TC and CC showed similar concentration levels, while $p, p^{\prime}$-DDT was 77 times higher (Table S3), indicating there were still fresh input of DDTs and chlordanes to the water phase as discussed above. The significant decrease of $\alpha-\mathrm{HCH}$ concentration in the equatorial Indian Ocean seawater from $100-1200 \mathrm{pg} \mathrm{L}^{-1}$ in $1989^{4}$ to $0.21-1.7 \mathrm{pg} \mathrm{L}^{-1}$ in 2011 should be related to the diffusion by the North Equatorial Current and volatilization into the atmosphere and consequent transport to the higher latitude. What is more, in situ hydrolysis and biological degradation processes also play important roles. ${ }^{7,31}$ According to the calculation method reported by Ngabe et al., ${ }^{32}$ the rate constant of hydrolysis in the equatorial Indian Ocean seawater at $\mathrm{pH} 8$ and $30{ }^{\circ} \mathrm{C}$ would be $3.32 \mathrm{y}^{-1}$, substantially higher than that in the eastern Arctic Ocean $\left(0.011 \mathrm{y}^{-1}\right)^{7}$ and the arctic Amituk Lake $\left(0.022 \mathrm{y}^{-1}\right)^{33}$ due to much higher water temperature in the target area. The higher hydrolysis rate constant would result in faster elimination of
$\alpha$-HCH from the equatorial Indian Ocean than from the Arctic region.

Air-Water Exchange. Previous studies identified air-water gas exchange as a very important process affecting POPs' distribution in the atmosphere. ${ }^{34}$

Fugacities in air $\left(f_{a}\right)$ and water $\left(f_{w}\right)$ and the fugacity fraction $(f f)$ were calculated according to the following equations ${ }^{12}$

$$
\begin{aligned}
& f_{a}=C_{a} R T \\
& f_{w}=C_{w} H \\
& f f=f_{w} /\left(f_{w}+f_{a}\right)
\end{aligned}
$$

where $C_{a}$ and $C_{w}$ are concentrations of chemical in air and water $\left(\mathrm{mol} \mathrm{m}^{-3}\right), R$ is the gas constant $\left(8.314 \mathrm{~Pa} \mathrm{~m}^{3} \mathrm{~mol}^{-1} \mathrm{~K}^{-1}\right), T$ is the absolute temperature $(\mathrm{K})$ in the air, and $H$ is the Henry's law constant $\left(\mathrm{Pa} \mathrm{m} \mathrm{mol}^{-1}\right)$. For these calculations an average temperature of $303 \mathrm{~K}$ based on the average seawater temperature $\left(29.5 \pm 0.3{ }^{\circ} \mathrm{C}, n=19\right)$ was used, along with temperaturecorrected $H$ values of selected OCPs (SI). $f f=0.5$ indicates airwater equilibrium, $f f<0.5$ indicates net deposition from air to the water, and $f f>0.5$ indicates volatilization from the water. ${ }^{12}$ Uncertainty of $f f$ calculation is based on the error from the measurement of $C_{a}, C_{w}$, and $H$ values. In this study, uncertainty of $45 \%$ was used according to Zhang et al., ${ }^{12}$ which means that $f f$ 

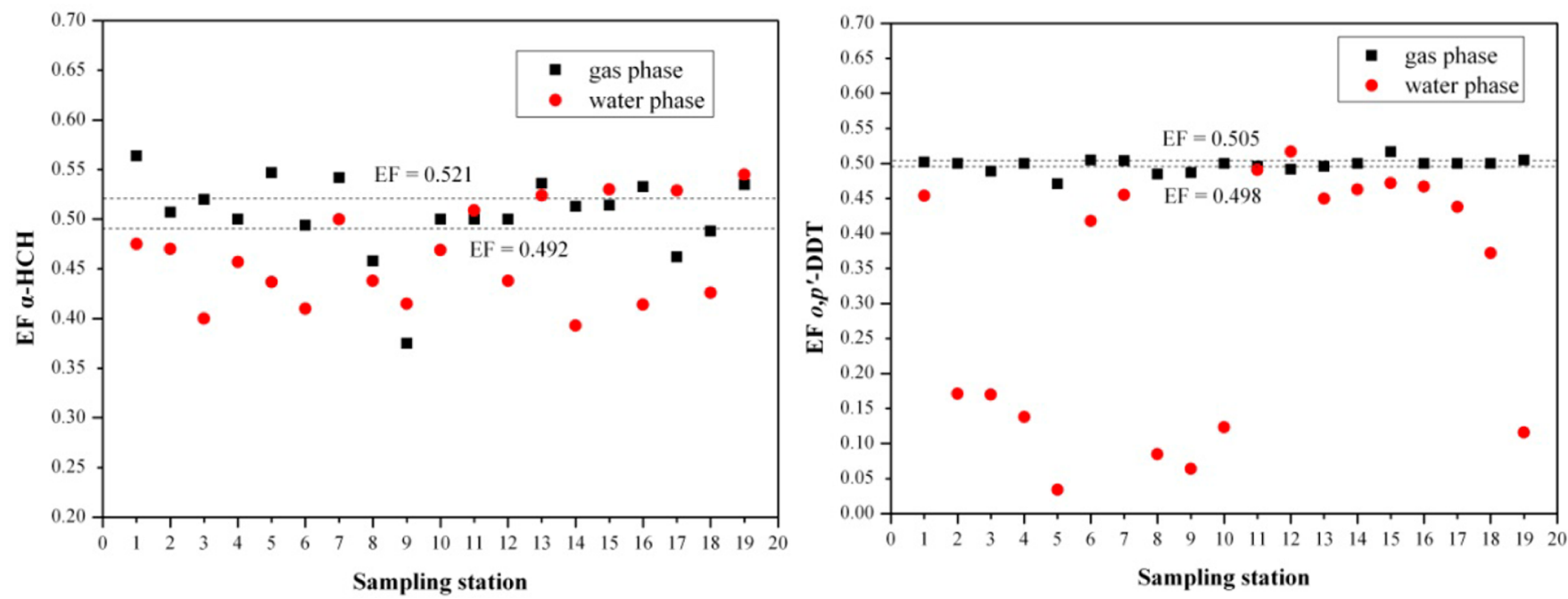

Figure 4. EFs of $\alpha-\mathrm{HCH}$ and $o, p^{\prime}$-DDT in gas and water phase along the sampling cruise. (The dot lines indicate the racemic window at $95 \%$ confidence.)

between 0.275 and 0.725 is considered as not significantly different from air-water equilibrium (Figure S1).

Figure $\mathrm{S} 1$ demonstrates that $\alpha-\mathrm{HCH}$ was found to be at equilibrium in almost all the stations, with an exception of Station 10 where volatilization was observed. For $\gamma-\mathrm{HCH}$, air-water equilibrium was found at ten stations, with volatilization at Station 14, and net deposition at the remaining eight stations. Status of equilibrium or near equilibrium of $\alpha-\mathrm{HCH}$ was also observed for most sampling at the North Atlantic Ocean in 2008, ${ }^{11}$ the Hudson Bay and Labrador Sea during 2007 to $2008,{ }^{18}$ while Lohmann et al. reported deposition for $\alpha-\mathrm{HCH}$ in the North Atlantic and Arctic Ocean in $2004 .^{8} \gamma-\mathrm{HCH}$ was reported to be undergoing deposition in the North Atlantic and Arctic Ocean in many recent studies. ${ }^{8,10,18}$

The air-water exchange direction of $p, p^{\prime}$-DDT, $o, p^{\prime}$-DDT, $p, p^{\prime}$-DDD, and $p, p^{\prime}$-DDE was predominantly from water to the air. Equilibrium or deposition was also found in a few stations due to the quite low concentrations in the water phase, especially in Stations 4, 9, 10, and 11. This is different from those observed in the North Atlantic and Arctic Ocean area, where net deposition was found for $p, p^{\prime}$-DDE in 2004, ${ }^{8}$ although net evaporation for $p, p^{\prime}$-DDE was also found after the bloom in 2008. ${ }^{11}$ Similar to DDT compounds, volatilization from the water was observed at most stations for TC, CC, and heptachlor, and status of near to equilibrium or net deposition was found at some stations (Figure S1). Zhang et al. ${ }^{11}$ reported air-water exchange of TC and CC was mostly from water to the air in the North Atlantic in 2008.

Enantiomer Signatures of Chiral OCPs. $\alpha-H C H$. By far, $\alpha-\mathrm{HCH}$ is the most extensively investigated chiral compound in the environment. Preferential degradation of $(+) \alpha-\mathrm{HCH}$ was observed in most cases, by virtue of enantiomeric signatures, especially in the Arctic region. For example, EFs suggested depletion of $(+) \alpha-\mathrm{HCH}$ in the air over the North Pacific Ocean and the adjacent Arctic region $(\mathrm{EF}=0.414 \pm 0.052)$ in $2003,{ }^{9}$ the North Atlantic and the Arctic Ocean $(E F=0.46 \pm 0.02)^{8}$ in 2004, and the North Atlantic $(\mathrm{EF}=0.463 \pm 0.023)$ in $2008 .{ }^{11}$ Wong et al. ${ }^{18}$ reported EFs of $0.456 \pm 0.008$ and $0.476 \pm 0.010$ in the air over the Labrador Sea and Beaufort Sea, respectively. However, in this study, racemic or near racemic composition was observed in most air samples with average EF of $0.505 \pm 0.042$, although selective depletion of $(+)$ or $(-) \alpha-\mathrm{HCH}$ has also been found in a few samples (Figure 4). This is similar to the results reported for the Atlantic cruise in $2001(\mathrm{EF}=0.493 \pm 0.018){ }^{35}$ with depletion of $(-) \alpha-\mathrm{HCH}$ in a couple of air samples.

In the water phase, degradation of $(+) \alpha-\mathrm{HCH}$ was found in most samples with an average EF of $0.430 \pm 0.025$, but degradation of $(-) \alpha-\mathrm{HCH}$ was found in four samples (Figure 4). Depletion of $(+) \alpha-\mathrm{HCH}$ was also observed in water samples from the North Atlantic and Arctic Ocean (EF: 0.430-0.50 and 0.442$0.454^{11}$ ), the Canadian Arctic seas (EFs: $\left.0.425-0.457\right),{ }^{18}$ the Arctic lakes (EFs: $0.359-0.432$, converted from enantiomer ratio), ${ }^{36}$ and the Yukon lakes (EFs: $0.237-0.468$, converted from enantiomer ratio). ${ }^{36}$ Law et al. ${ }^{36}$ surmised that enantioselective degradation would be enhanced under low nutrient conditions as oligotrophic bacteria have the ability to use xenobiotics carbon source such as $\alpha$-HCH. However, although abundant carbon sources are provided in the equatorial Indian Ocean, comparable or even greater depletion of $(+) \alpha-\mathrm{HCH}$ than that in the Arctic region was found in half of the water samples (EFs: 0.393-0.438) in this study. It implies that eutrophic microbes can also metabolize or cometabolize $\alpha-\mathrm{HCH}$ in seawater. What is more, the diversity of microbes in this area may allow degradation of both $(+) \alpha-\mathrm{HCH}$ and $(-) \alpha-\mathrm{HCH}$.

$o, p^{\prime}-D D T$. Enantiomeric signatures of $o, p^{\prime}$-DDT in oceans have been rarely reported. In this study, $o, p^{\prime}$-DDT in the air was

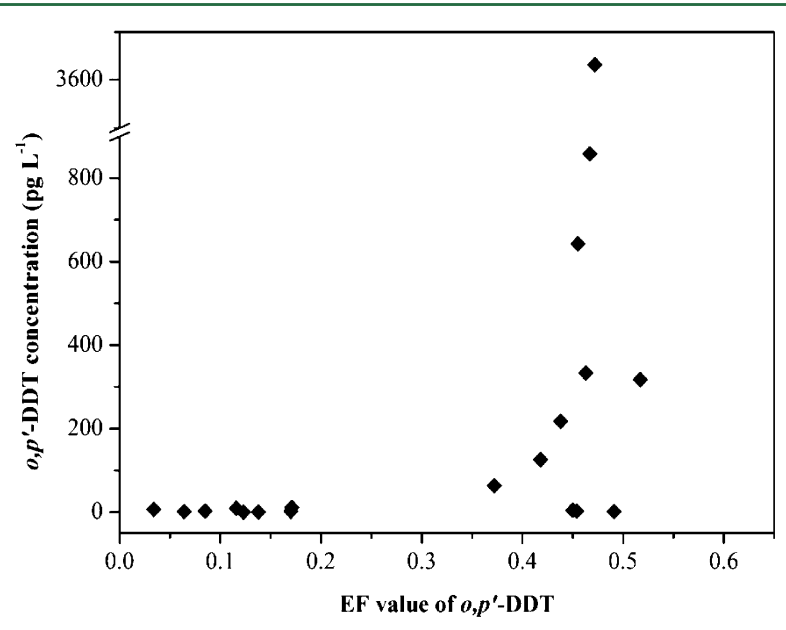

Figure 5. Enantiomer fraction values and concentrations of $o, p^{\prime}-\mathrm{DDT}$ in water samples. 

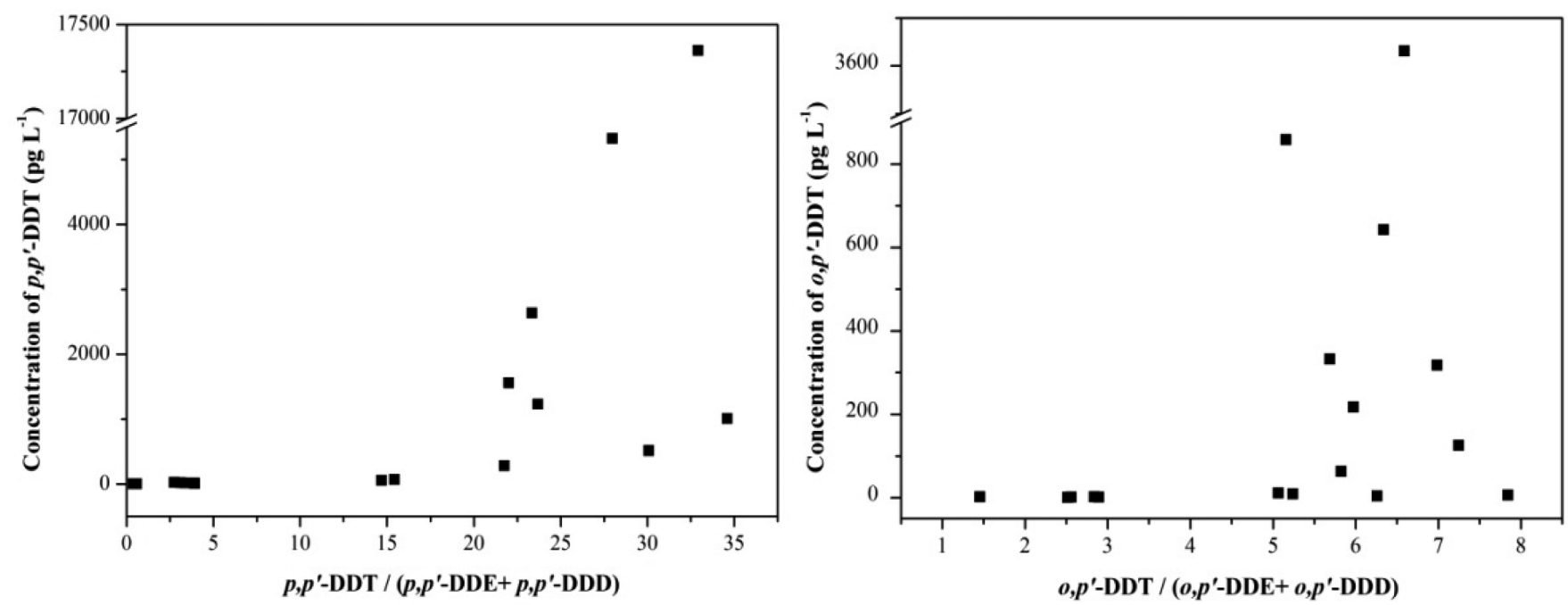

Figure 6. Concentrations of $p, p^{\prime}-\mathrm{DDT}$ and $o, p^{\prime}-\mathrm{DDT}$ and the ratios of DDT/(DDE + DDD) in water samples.

found to be racemic and nearly racemic, with average EF of $0.497 \pm 0.01$.

Significant depletion of $(+) o, p^{\prime}$-DDT was found in most of the water samples (EFs: 0.034-0.491, $0.299 \pm 0.176$ ) and slight depletion of $(-) o, p^{\prime}$-DDT in one sample $(\mathrm{EF}=0.517)$ as demonstrated in Figure 4. We found that $o, p^{\prime}$-DDT concentrations in the water phase were strongly related to EFs (Figure 5), i.e., in the stations with high concentrations of $o, p^{\prime}$-DDT (220-3600 pg L ${ }^{-1}$ ), near racemic compositions were found (EFs: $0.438-0.517$ ), while significant nonracemic $o, p^{\prime}$-DDT (EFs: $0.034-0.171)$ coincided with the low concentrations of $o, p^{\prime}$-DDT $\left(<12 \mathrm{pg} \mathrm{L}^{-1}\right)$. This is consistent with the $\mathrm{DDT} /(\mathrm{DDE}$ $+\mathrm{DDD}$ ) distribution in the water phase (Figure 6), where high $\mathrm{DDT} /(\mathrm{DDE}+\mathrm{DDD})$ ratios $\left(22-35\right.$ for $p, p^{\prime}$-DDT and 5.2-7.0 for $o, p^{\prime}$-DDT) were observed in the water samples with high DDT concentrations and vice versa. This may be because that the water samples with high concentrations of DDT were mixed with fresh and less microbially degraded input, which would cause the increase of EFs and DDT/(DDE+DDD) ratios in those samples. For example, the DDT/(DDD+DDE) ratios in Stations 15 and 16 were 33 and 28 for $p, p^{\prime}$-isomers and 6.6 and 5.2 for $o, p^{\prime}$-isomers, with EFs of 0.472 and 0.467 , respectively. At the stations with low DDT concentrations, EFs and DDT/(DDD + DDE) ratios, microbially degraded "old" DDT might be the main source.

Long-Range Transport vs Volatilization. EFs could be used to trace the sources of chiral compounds in the air over large lakes and oceans. Studies suggested that EFs in the air over those systems varied from nearly racemic when long-range transport dominated to nonracemic upon volatilization from water. ${ }^{9,10,17,18}$ For example, a decrease in EFs in the air over the Resolute Bay $(\mathrm{EF}=0.483 \pm 0.009)^{10}$ and the Beaufort Sea $(\mathrm{EF}=0.476 \pm$ $0.010)^{18}$ of the Canadian Arctic Ocean was found after ice breakup which allowed nonracemic $\alpha-\mathrm{HCH}$ to volatilize from the seawater and mix in the air boundary layer with the nearly racemic $\alpha$-HCH advected by long-range transport.

The fraction $\left(f_{c}\right)$ of chiral compound in the air from local seawater was estimated using the following formula ${ }^{10,11}$

$$
f_{c}=\left(E_{\mathrm{a}}-\mathrm{EF}_{\mathrm{b}}\right) /\left(\mathrm{EF}_{\mathrm{w}}-\mathrm{EF}_{\mathrm{b}}\right)
$$

where $\mathrm{EF}_{\mathrm{a}}$ and $\mathrm{EF}_{\mathrm{w}}$ refer to $\mathrm{EF}$ values in the boundary air and surface seawater, respectively, $\mathrm{EF}_{\mathrm{b}}$ is the average $\mathrm{EF}$ in background air. $\mathrm{EF}_{\mathrm{b}}$ was assumed to be the average EFs of the chiral compound standards, i.e., 0.507 for $\alpha-\mathrm{HCH}$ and 0.502 for $o, p^{\prime}$-DDT. Because an individual air sample represented the levels of a large scale from the start location to the end location, while a water sample was collected at one certain station along the present air sampling event, using EFs of one-to-one air and water samples would cause large deviations and even result in negative contribution values. Therefore, average EFs in the air and water samples along the sampling cruise were used to evaluate the $f_{\mathrm{c}}$ according to previous studies. ${ }^{10,11}$ Since Stations 1, 2, 3,15 , and 16 were located near the continent, and the air-water gas exchange processes there would be influenced by the continental riverine input and atmospheric deposition, they were excluded from the calculation.

The result showed that $24 \%$ of $\alpha-\mathrm{HCH}$ in the lower air over the open sea of the equatorial Indian Ocean was from local seawater volatilization, lower than the fractions in the Resolute Bay after ice breakup (32\%), ${ }^{10}$ North Atlantic (52\%), ${ }^{11}$ and Kattegat Sea during the summer months $(20-50 \%) .{ }^{37}$ This implies that $\alpha-\mathrm{HCH}$ in the air over the equatorial Indian Ocean during the sampling cruise mainly came from long-range transport, which is consistent with the oceanic air masses observed. For $o, p^{\prime}$-DDT, the $f_{\mathrm{c}}$ was $3.0 \%$, although $f f_{\mathrm{s}}$ predicted net volatilization for $o, p^{\prime}$-DDT in most cases, indicating that removing $o, p^{\prime}$-DDT from water via volatilization was a long-term process, even in the ocean with high sea surface temperature.

\section{ASSOCIATED CONTENT}

\section{Supporting Information}

Detailed information on sample extraction and cleanup, instrumental analysis of both achiral and chiral OCPs, breakthrough check of air and water sampling, selection of Henry's Law constants and additional figures and tables. This material is available free of charge via the Internet at http://pubs.acs.org.

\section{AUTHOR INFORMATION}

\section{Corresponding Author}

*Phone: +86-20-85290178. Fax: +86-20-85290706. E-mail: xuyue@gig.ac.cn.

Notes

The authors declare no competing financial interest. 


\section{ACKNOWLEDGMENTS}

This work was supported by the Chinese Academy of Sciences (No. KZCX2-YW-GJ02) and the Natural Science Foundation of China (NSFC) (Nos. 41125014 and 41073080). In addition, the authors would like to thank the National Oceanic and Atmospheric Administration's Air Resources Laboratory for providing the HYSPLIT transport model and the READY Web site (http://www.arl.noaa.gov/ready.html). This is a contribution of GIGCAS-1773.

\section{REFERENCES}

(1) Jones, K. C.; de Voogt, P. Persistent organic pollutants (POPs): state of the science. Environ. Pollut. 1999, 100 (1-3), 209-221.

(2) Wania, F.; Mackay, D. Tracking the distribution of persistent organic pollutants. Environ. Sci. Technol. 1996, 30 (9), A390-A396.

(3) Dachs, J.; Lohmann, R.; Ockenden, W. A.; Mejanelle, L.; Eisenreich, S. J.; Jones, K. C. Oceanic biogeochemical controls on global dynamics of persistent organic pollutants. Environ. Sci. Technol. 2002, 36 (20), 4229-4237.

(4) Iwata, H.; Tanabe, S.; Sakai, N.; Tatsukawa, R. Distribution of persistent organochlorines in the oceanic air and surface seawater and the role of ocean on their global transport and fate. Environ. Sci. Technol. 1993, 27 (6), 1080-1098.

(5) Stemmler, I.; Lammel, G. Cycling of DDT in the global environment 1950-2002: World ocean returns the pollutant. Geophys. Res. Lett. 2009, 36 (24), L24602.

(6) Li, Y. F.; Bidleman, T. F. Correlation between global emissions of $\alpha$-hexachlorocyclohexane and its concentrations in the Arctic air. J. Environ. Inf. 2003, 1 (1), 52-57.

(7) Harner, T.; Kylin, H.; Bidleman, T. F.; Strachan, W. M. J. Removal of $\alpha$ - and $\gamma$-hexachlorocyclohexane in the eastern arctic ocean. Environ. Sci. Technol. 1999, 33, 1157-1164.

(8) Lohmann, R.; Gioia, R; Jones, K. C.; Nizzetto, L.; Temme, C.; Xie, Z.; Schulz-Bull, D.; Hand, I.; Morgan, E.; Jantunen, L. Organochlorine pesticides and PAHs in the surface water and atmosphere of the North Atlantic and Arctic Ocean. Environ. Sci. Technol. 2009, 43, 5633-5639.

(9) Ding, X.; Wang, X.-M.; Xie, Z.-Q.; Xiang, C.-H.; Mai, B.-X.; Sun, L.G.; Zheng, M.; Sheng, G.-Y.; Fu, J.-M. Atmospheric hexachlorocyclohexanes in the North Pacific Ocean and the adjacent Arctic region: Spatial patterns, chiral signatures, and sea-air exchanges. Environ. Sci. Technol. 2007, 41, 5204-5209.

(10) Jantunen, L. M.; Helm, P. A.; KyLin, H.; Bidleman, T. F. Hexachlorocyclohexanes (HCHs) in the Canadian Archipelago. 2. Air-water gas exchange of $\alpha$ - and $\gamma-\mathrm{HCH}$. Environ. Sci. Technol. 2008, 42, 465-470.

(11) Zhang, L.; Bidleman, T. F.; Perry, M. J.; Lohmann, R. Fate of chiral and achiral organochlorine pesticides in the North Atlantic bloom experiment. Environ. Sci. Technol. 2012, 46, 8106-8114.

(12) Zhang, G.; Li, J.; Cheng, H.; Li, X.; Xu, W.; Jones, K. C. Distribution of organochlorine pesticides in the Northern South China Sea: Implications for land outflow and air-sea exchange. Environ. Sci. Technol. 2007, 41, 3884-3890.

(13) Lin, T.; Li, J.; Xu, Y.; Liu, X.; Luo, C.; Cheng, H.; Chen, Y.; Zhang, G. Organochlorine pesticides in seawater and the surrounding atmosphere of the marginal seas of China: Spatial distribution, sources and air-water exchange. Sci. Total Environ. 435-436, 244-252.

(14) Wurl, O.; Potter, J. R.; Obbard, J. P.; Durville, C. Persistent organic pollutants in the equatorial atmosphere over the open Indian Ocean. Environ. Sci. Technol. 2006, 40, 1454-1461.

(15) Gioia, R.; Li, J.; Schuster, J.; Zhang, Y.; Zhang, G.; Li, X.; Spiro, B.; Bhatia, R. S.; Dachs, J.; Jones, K. C. Factors affecting the occurrence and transport of atmospheric organochlorines in the China Sea and the Northern Indian and South East Atlantic Oceans. Environ. Sci. Technol. 2012, 46, 10012-10021.

(16) UNEP, Regional based assessment of persistent toxic substances---Indian Ocean Regional Report. 2002; p 15. http://www. chem.unep.ch/pts/regreports/IndianOcean.pdf (accessed November 5, 2013).
(17) Bidleman, T. F.; Jantunen, L. M. M.; Kurt-Karakus, P. B.; Wong F. Chiral persistent organic pollutants as tracers of atmospheric sources and fate: review and prospects for investigating climate change influences. Atmos. Pollut. Res. 2012, 3, 371-382.

(18) Wong, F.; Jautunen, L. M.; Pućko, M.; Papakyriakou, T.; Staebler, R. M.; Stern, G. A.; Bidleman, T. F. Air-Water exchange of anthropogenic and natural organohalogens on International Polar Year (IPY) expeditions in the Canadian Arctic. Environ. Sci. Technol. 2011, 45, 876-881.

(19) Meng, X.-Z.; Guo, Y.; Mai, B.-X.; Zeng, E. Y. Enantiomeric signatures of chiral organochlorine pesticides in consumer fish from South China. J. Agric. Food. Chem. 2009, 57, 4299-4304.

(20) Genualdi, S. A.; Simonich, S. L. M.; Primbs, T. K.; Bidleman, T. F.; Jantunen, L. M.; Ryoo, K.-S.; Zhu, T. Enantiomeric signatures of organochlorine pesticides in Asian, trans-Pacific, and Western U.S. air masses. Environ. Sci. Technol. 2009, 43, 2806-2811.

(21) Draxler, R. R.; Rolph, G. D. NOAA Air Resources Laboratory: Silver Spring, MD, 2003.

(22) Rolph, G. D. Real-time Environmental Applications and Display System (READY) Website; NOAA Air Resources Laboratory: Silver Spring, MD, 2003. http://www.arl.noaa.gov/ready/hysplit.html (accessed November 5, 2013).

(23) UNEP, Regional based assessment of persistent toxic substances---South East Asia and South Pacific Regional Report. 2002; p 27. http://www.chem.unep.ch/pts/regreports/seaandsp.pdf (accessed November 5, 2013).

(24) Wu, X.; Lam, J. C. W.; Xia, C.; Kang, H.; Sun, L.; Xie, Z.; Lam, P. K. S. Atmospheric $\mathrm{HCH}$ concentrations over the marine boundary layer from Shanghai, China to the Arctic Ocean: Role of human activity and climate change. Environ. Sci. Technol. 2010, 44, 8422-8428.

(25) Dearth, M. A.; Hites, R. A. Complete analysis of technical chlordane using negative ionization mass spectrometry. Environ. Sci. Technol. 1991, 25, 245-254.

(26) Jantunen, L. M. M.; Bidleman, T. F.; Harner, T.; Parkhurst, W. J. Toxaphene, chlordane, and other organochlorine pesticides in Alabama air. Environ. Sci. Technol. 2000, 34, 5097-5105.

(27) Li, J.; Zhang, G.; Qi, S.; Li, X.; Peng, X. Concentrations, enantiomeric compositions, and sources of $\mathrm{HCH}, \mathrm{DDT}$ and chlordane in soils from the Pearl River Delta, South China. Sci. Total Environ. 2006, $372,215-224$.

(28) Iwata, H.; Tanabe, S.; Sakai, N.; Nishimura, A.; Tatsukawa, R. Geographical distribution of persistent organochlorines in air, water and sediments from Asia and Oceania, and their implications for global redistribution from lower latitudes. Environ. Pollut. 1994, 85, 15-33.

(29) Macdonald, R.; McLaughlin, F.; Adamson, L. The Arctic OceanThe last refuge of volatile organochlorines. Can. Chem. News 1997, 49, $28-29$.

(30) Gupta, P. K. Pesticide exposure-Indian scene. Toxicology 2004, 198, 83-90.

(31) Galbán-Malagón, C. J.; Berrojalbiz, N.; Gioia, R.; Dachs, J. The "degradative" and "biological " pumps controls on the atmospheric deposition and sequestration of hexachlorocyclohexanes and hexachlorobenzene in the North Atlantic and Arctic Oceans. Environ. Sci. Technol. 2013, 47, 7195-7203.

(32) Ngabe, B.; Bidleman, T. F.; Falconer, R. L. Base hydrolysis of $\alpha$ and $\gamma$-hexachlorocyclohexanes. Environ. Sci. Technol. 1993, 27, 19301933.

(33) Helm, P. A.; Diamond, M. L.; Semkin, R.; Bidleman, T. F. Degradation as a loss mechanism in the fate of $\alpha$-hexachlorocyclohexane in arctic watersheds. Environ. Sci. Technol. 2000, 34, 812-818.

(34) Nizzetto, L.; Macleod, M.; Borgå, K.; Cabrerizo, A.; Dachs, J.; Guardo, A. D.; Ghirardello, D.; Hansen, K. M.; Jarvis, A.; Lindroth, A.; Ludwig, B.; Monteith, D.; Perlinger, J. A.; Scheringer, M.; Schwendenmann, L.; Semple, K. T.; Wick, L. Y.; Zhang, G.; Jones, K. C. Past, present, and future controls on levels of persistent organic pollutants in the global environment. Environ. Sci. Technol. 2010, 44, $6526-6531$ 
(35) Covaci, A.; Gheorghe, A.; Meijer, S.; Jaward, F.; Jantunen, L.; Neels, H.; Jones, K. C. Investigation of source apportioning for $\alpha-\mathrm{HCH}$ using enantioselective analysis. Environ. Int. 2010, 36, 316-322.

(36) Law, S. A.; Diamond, M. L.; Helm, P. A.; Jantunen, L. M.; Alaee, $M$. Factors affecting the occurrence and enantiomeric degradation of hexachlorocyclohexane isomers in northern and temperate aquatic systems. Environ. Toxicol. Chem. 2001, 20, 2690-2698.

(37) Sundqvist, K. L.; Wingfors, H.; Brorstrom-Lundren, E.; Wiberg, K. Air-sea gas exchange of $\mathrm{HCHs}$ and PCBs and enantiomers of $\alpha-\mathrm{HCH}$ in the Kattegat Sea region. Environ. Pollut. 2004, 128, 73-83. 